\title{
Atividade hemaglutinante em sementes de Bauhinia subclavata Benth e Crotalaria spectabilis Roth
}

\section{Actividad hemaglutinante en semillas de Bauhinia subclavata Benth y Crotalaria spectabilis Roth}

DOI: $10.46814 / \operatorname{lajdv3n3-051}$

Recebimento dos originais: 01/052021

Aceitação para publicação: 31/06/2021

\section{Vera Regiane Brescovici Nunes}

Doutora em Ciências da Religião.Graduada em Artes e Pedagogia. Mestre em História. Pesquisadora sobre Pinturas Rupestres da Região Oeste da Bahia. Professora Adjunta da Universidade Federal do Oeste da Bahia - UFOB. Santa Maria da Vitória - Bahia.

E-mail: veraregiane@yahoo.com.br

\section{RESUMO}

O trabalho em questão apresenta um fragmento da pesquisa realizada sobre grafismos rupestres (pinturas) encontrados nos sítios arqueológicos Morro do Sol e Pedras Brilhantes ou Morro dos Tapuias, localizados no município de São Desidério no Estado da Bahia. Foram pesquisadas as pinturas presentes nos locais a partir da utilização das imagens fotográficas lá produzidas. Essas imagens foram comparadas com a de outros sítios presentes no território brasileiro, principalmente na região nordeste. O objetivo foi por meio da comparação, identificar uma possível tradição rupestre. Também, se comparou o contexto cronoestilístico, as cores, formas e traços. Essas manifestações têm sido analisadas ao longo do tempo, sob diferentes vertentes da arqueologia, cultura, religião e arte. A pintura rupestre é uma forma de linguagem pictográfica que foi utilizada para retratar possivelmente a vida cotidiana das primeiras civilizações. Utilizaram como suporte as paredes de cavernas, paredões e abrigos entre outros, para proceder seus registros. Atualmente, o grafite e outras linguagens contemporâneas fazem uso do suporte parietal. A análise foi fundamentada em autores que desenvolvem trabalhos na área, como os que vêm sendo realizados em todo o estado baiano pelos pesquisadores da Universidade Federal da Bahia.

Palavras - Chave: Pintura Rupestre. Grafismos. Sítios Arqueológicos.

\begin{abstract}
The work in question presents a fragment of the research carried out on rock art (paintings) found in the archaeological sites Morro do Sol and Pedras Brilhantes or Morro dos Tapuias, located in the municipality of São Desidério in the State of Bahia. The paintings present in the places were researched using the photographic images produced there. These images were compared with those of other sites present in the Brazilian territory, mainly in the northeast region. The objective was, through comparison, to identify a possible rock tradition. Also, the chrono-stylistic context, colors, shapes and lines were compared. These manifestations have been analyzed over time, under different aspects of archeology, culture, religion and art. Cave painting is a form of pictographic language that was used to possibly portray the everyday life of early civilizations. They used as support the walls of caves, walls and shelters, among others, to carry out their records. Currently, graffiti and other contemporary languages make use of parietal support. The analysis was based on authors who develop works in the area, such as those being carried out throughout the state of Bahia by researchers from the Federal University of Bahia.
\end{abstract}


Key words: Rock Painting. Graphics. Archaeological Sites.

\section{INTRODUÇÃO}

As manifestações rupestres têm sido analisadas ao longo do tempo, sob diferentes modelos explicativos da arqueologia. A expressão "arte rupestre", também chamada de arte parietal, é etimologicamente derivada do latim: "rupes" (rocha) e refere-se aos testemunhos gráficos das sociedades do passado, deixados sobre as paredes e tetos de cavernas. (WUST, 1991).

As referências sobre essa arte já se manifestavam desde o século XVI, na Europa. Mas, o reconhecimento e a necessidade em compreendê-la a partir de diferentes contextos, como o religioso e o simbólico ocorreram mais tarde (SILVA, 2012). Presume-se que as primeiras conexões entre as evidências etnográficas e o registro arqueológico tenham sido concebidas nos primórdios da teoria evolucionista no final do século XIX, quando houve pela primeira vez a relação entre culturas atuais e de "povos-primitivos" e culturas pré-históricas do paleolítico. Segundo (SILVA, 2002), essas obras não resultaram de pesquisas etnográficas no sentido antropológico, mas do resultado de relatos e publicações da época.

Foi somente no início do século XX que os registros rupestres foram associados à função utilitário-religiosa, numa perspectiva cientifica influenciada pela teoria evolucionista. Os registros rupestres são representações que registram o legado cultural de determinados povos em determinadas épocas. O termo 'representação' provém da forma latina "repraesentare" - fazer - se presente ou apresentar de novo. Fazer presente alguém ou alguma coisa ausente, inclusive uma ideia, por intermédio da presença de um objeto. (SANTAELA, 2008).

Ainda no XX, a representação foi entendida como um sistema de comunicação. Do ponto de vista da semiologia, passou a ser considerado um código simbólico, que deveria ser decifrado, como um texto. Em analogia à linguagem, os artefatos seriam sistemas de signos que comunicariam significados não verbais inseridas em uma visão de conjunto, buscando-se a organização interna nos painéis.

Para a semiótica a linguagem é uma forma de representação que permite aos seres humanos perceber e inserir-se na realidade. Representa o legado cultural dos povos em geral. Para Pierce (apud MARTINS, 1998, p.39), as imagens que vêm da Pré-História, são signos e representam o pensamento do homem. "Um signo é uma coisa que representa outra coisa: seu objeto (ideia ou coisa) para alguém sob algum aspecto ou qualidade" Portanto, a penetração na realidade, é sempre mediada por linguagens, por sistemas simbólicos. Uma construção que se realiza pela representação de objetos, ideias e conceitos, por meio dos diferentes sistemas simbólicos. 
As primeiras descrições sobre figuras rupestres de forma mais científica no território brasileiro datam do século XVIII. O despertar da pesquisa arqueológica para a importância dos sítios arqueológicos ocorreu a partir das descobertas de Peter Lund na Gruta de lagoa Santa Minas Gerais.

Nas últimas décadas um grande número de pesquisas envolvendo vestígios rupestres têm se intensificado em todo Brasil. Na região sul a existência de sítios é reduzida se comparado aos estados de Minas Gerais, Goiás, Bahia, Piauí, entre outros. No Estado da Bahia há um grande número de sítios arqueológicos. Alguns apresentam apenas pinturas ou gravuras, outros artefatos líticos, urnas, e outros. O município de Central localizado ao norte do estado da Bahia e regiões circunvizinhas se destaca pela concentração de vestígios rupestres. O estado do Piauí, mais precisamente em São Raimundo Nonato, é a região que apresenta uns grandes acervos já pesquisados de vestígios rupestres. Na década de 1980, segundo Prous (1991) e outros, os trabalhos realizados de sul a norte com base na variedade estilística encontrada em sítios brasileiros definiram oito tradições e algumas sub-tradições como: Meridional, Agreste, Nordeste, Geométrica, Litorânea Catarinense, Planalto, São Francisco e Amazônica que são utilizadas para caracterizar grafismos encontrados nas regiões brasileiras.

O presente texto relata a pesquisa realizada em dois sítios arqueológicos na região oeste baiana, a partir de análises fotográficas, em que se discorreu sobre a tipologia, estilos e tradições encontrados, fundamentados em estudos realizados por autores em outras regiões brasileiras. Essa análise cronoestilistica se processou baseada em: Ribeiro (2006); Oliveira (2006); Prous (2006); Costa (2005); Etchevarne (2011); Comerlato (2007); Falcón (2012); Silva (2002), e outros. Para registrar as informações e proceder à análise foram utilizadas imagens fotográficas produzidas no local.

\section{DIÁLOGOS E INTERAÇÕES}

A expressão "arte rupestre”, também chamada de arte parietal, é etimologicamente derivada do latim: "rupes" (rocha) e refere-se aos testemunhos gráficos das sociedades do passado, deixados sobre as paredes e tetos de cavernas, abrigos-sob-rocha ou lajes a céu aberto (WUST, 1991, p. 47). Essas manifestações têm sido analisadas ao longo do tempo, sob diferentes modelos explicativos da arqueologia. Silva (2002) propõe uma análise na ótica de dois polos distintos: o que remete ao estudo do grafismo, e outro, que prioriza as condições que propiciam a produção dos próprios grafismos que envolvem o socioeconômico, ecológico, entre outros.

No século XVI, na Europa, já se encontravam referências às pinturas existentes na gruta de Niaux, mas, o reconhecimento como "vestígios arqueológicos e a necessidade de estudá-los a partir de um contexto simbólico religioso ocorreu somente mais tarde”. (SILVA, 2002, p.14) Para a autora, as primeiras conexões entre as evidências etnográficas e o registro arqueológico são sugeridas nas obras, "Primitive Culture" e o "Ramo de Ouro". Ambas concebidas nos primórdios da teoria evolucionista no 
final do século XIX, quando houve pela primeira vez a relação entre culturas atuais e de "povosprimitivos e culturas pré-históricas do paleolítico".

Na nova proposta criada nos anos de 1960, foram modificadas as formas de leitura dos grafismos, que se efetivavam a partir de uma linguagem analítica e sistemática. "Muda-se o método em função de novo objeto”. (SILVA, 2012, p.18). Analisa-se o objeto o signo e não as analogias etnográficas. As representações rupestres passam a ser consideradas como um conjunto significativo, cujas unidades se relacionam entre si, tanto do todo como das partes.

\subsection{TRADIÇÕES E ESTILOS RUPESTRES BRASILEIROS}

Para Ribeiro (2006), o conceito de tradição arqueológica foi introduzido no Brasil por Betty Meggers e Clifford Evans na década de 1960. Com o objetivo de fornecer um quadro geral das culturas arqueológicas brasileiras a curto prazo. A utilização dessas categorias seria para identificar as variantes culturais ou étnicas na distribuição crono- geográfica dos artefatos, que se alinhava mais ao difusionismo cultural europeu que ao neo- evolucionismo de onde se originaram as noções de tradição. Calderon em 1970 (apud RIBEIRO, 2006), trouxe a primeira ordenação seguindo esses moldes. O termo tradição foi definido pelo autor como,

(...) conjunto de características que se refletem em diferentes sítios ou regiões, associados de maneira similar, atribuindo cada uma delas ao complexo cultural de grupos étnicos diferentes que as transmitiram e difundiram gradualmente modificados, através do tempo e do espaço (CALDERÓN, 1983 [1967], apud COSTA, 2005, p. 145-6).

A referida definição propôs uma classificação para os sítios arqueológicos do sudeste baiano em tradições Simbolista e Realista. Definiu a Tradição Realista da seguinte forma Costa(2005),

\footnotetext{
O exame de uma série de pictografias nas quais é bem visível a intenção de reproduzir homens, animais e plantas, com o máximo rigor permitido pela habilidade técnica de seus autores, levou a identificação de uma forma de expressão artística que por sua difusão espacial e, provavelmente, temporal, suas características de fidelidade aos modelos que tentaram copiar, denominamos de Tradição Realista, cuja extensão geográfica parece ultrapassar os limites do Estado (CALDERÓN, 1983 [1967], p. 14 apud COSTA, 2005 p. 145).
}

Sobre a Tradição Simbolista descreve e conceitua como mais abundante e espalhada por todo país,

Geométrica ou grosseiramente figurativa, deve corresponder a povos marginais, com cultura muito primitiva. Encontramo-la na Caverna do Bode, na Serra Solta, no Rio São Francisco (Curaçá e Petrolina) e em diversos 38 pontos da Chapada, especialmente nos sopés desta, perto da estrada que vai de Irecê ao Morro do Chapéu. São sempre motivos isolados sem correlação aparente. Superpõem-se e misturam-se sem conservar nenhuma harmonia, variando bastante quanto à forma. Podem ser simples círculos ou espirais assim como complicados desenhos 
As classificações acima, não obtiveram êxito. Os padrões de similaridade, temática e estilística, seriam mais tarde adotados por arqueólogos de Minas Gerais e Piauí e outros independentes.

Ao longo das décadas de 1970 e 1980 as pesquisas sobre a arte rupestre brasileira nas regiões centrais e nordeste foram orientadas para as classificações estilísticas e descritas cinco tradições rupestres, além de diversos conjuntos gráficos classificados a partir de critérios distintos, conforme postula Ribeiro (2006, p.28), “tradições Nordeste, São Francisco, Geométrica, Agreste, Itacoatiaras e Planalto, sub-tradição Seridó; complexo Montalvânia, estilo Serranópolis, estilo Caiapônia, unidades estilísticas Piolho de Urubu e Desenhos”. A forma de classificação inicial das tradições e sub-tradições foi alvo de "questionamento por teóricos como Consens e Seda, que argumentaram terem sido mal definidas". (1989, apud, RIBEIRO, 2006).

Em se tratando das tradições Nordeste, São Francisco, Geométrica e Agreste, foram utilizadas a aplicação dessas categorias e identificadas em quase todo centro-nordeste, conforme Martin (1997); Pessis (2004); Prous (1992, 1994) entre outros.

Para Ribeiro (2006, p. 29), as tradições em geral "são definidas pela repetição de traços temáticos que indicaria continuidade cultural, correspondendo aos códigos ou repertórios partilhados por grupos separados no espaço no tempo ou em ambos." Conceito postulados por Calderón (1970); Martin (1997); Pessis e Guidon, (2000/1992)e Prous(1992, 1999).

Quanto ao estilo, nem todos os autores concordam alguns como Guidon e Pessis $(2000,1992$, apud, RIBEIRO, 2006), afirmam ser o "resultado da evolução de uma etnia em função do tempo, do isolamento geométrico, das influências exteriores.” Prous (1992, 1999 e SCHIMITZ e outros, 1984, apud, RIBEIRO, 2006, p.28), afirmam que "o estilo caracteriza períodos, territórios, limites geográficos e temporais de manifestação das tradições". Ambas as definições abordam que o estilo se diferencia pelas distintas abordagens a que foi submetido (morfologias e técnicas) determinado ou utilizado. A partir de 1990, abordagens teóricas das arqueologias estadunidenses e europeia, passaram a ser aplicadas ao passado pré- histórico do território brasileiro que com objetivo de elaborar estudos mais precisos de contextualização e datação das pinturas e gravuras rupestres. Há mais de trinta anos realizam-se, análises e descrições das tradições rupestres no Brasil.

Para Ribeiro (2006), essas pesquisas sistemáticas têm contribuído para maior detalhamento dos estilos e tradições encontradas em algumas regiões, e estimulado novas pesquisas na área. Autores como Isnardis (2004); Prous e Ribeiro (1996- 1997), entre outros, inserem-se nesse quadro. Isnardis (2004, apud, RIBEIRO, 2006), investigou em abrigos rochosos do Cânion do Rio Peruaçu (MG), e fez 
associações dos diferentes estilos encontrados no local às características físicas dos abrigos, observando se as qualidades físicas dos sítios poderiam ter sido consideradas na escolha para a realização de determinados estilos.

Na Serra da Capivara, estado do Piauí, após trinta anos de pesquisas alguns conjuntos significativos que haviam sido nomeados anteriormente foram reorganizados, revistos e discutidos a partir novas perspectivas sobre a arte local, apresentadas por Pessis em 2003, conforme descreve Ribeiro (2006),

em pesquisas anteriores havia sido identificada na região a Tradição geométrica, composta por características técnicas e morfológicas que distinguiam suas pinturas daquelas atribuídas às Tradições nordeste e Agreste dominante na região. Pessis considera não haver elementos que indiquem que os autores das figuras da Tradição Geométrica pertencessem a um grupo cultural único e distinto dos autores das demais figuras. (RIBEIRO, 2006, p. 31).

A investigação da arte rupestre a partir de outros recursos como os tecnológicos, já vem sendo utilizada e permite maior precisão nos dados. Segundo Ribeiro (2006), a tecnologia começou a ser utilizada no passado, mas não de forma contínua. Reflexões recentes sobre os processos de ocupação humana no território brasileiro têm sido realizadas e já se encontram disponíveis em bibliografias, como, (Dias, 2005; KIPNIS, 2002, 2003, apud RIBEIRO, 2006).

O conceito em vigor de tradição rupestre se pauta na ideia de que os "conjuntos de temas representados com mais frequência na arte rupestre são manifestações de repertórios culturais, donde repertórios temáticos distintos distinguem repertórios culturais" (RIBEIRO, 2006, p.48). Conceito que pode ser encontrado em autores como Prous(1999), Isnardis(2004), entre outros. Nessa abordagem, a cultura interfere e consequentemente ocasiona as mudanças demonstradas na continuidade gráfica.

Ribeiro (2006) afirma que tradição rupestre como repertório temático ou repertório cultural tem suas raízes na arqueologia e princípios estruturalistas nos primórdios da pesquisa sistemática. Tais ideias encontram suporte em autores como Lévi- Strauss (1955); Leroi-Gourhan (1965) e Laming(1962). E em outras correntes antropológicas não estruturalistas como em Geertz (1889).

Trabalhos realizados de sul a norte, e revistos ao longo da década de 1980 e posterior, sobre a variedade estilística encontrada em sítios rupestres brasileiros definiram oito tradições e algumas subtradições que foram denominados de: Meridional, Agreste, Nordeste, Geométrica, Litorânea Catarinense, Planalto, São Francisco e Amazônica. Essas tradições não serão descritas nesse texto, pela especificidade do mesmo. 


\subsection{REGIÃO OESTE BAIANA}

A região conhecida hoje como "Oeste", já foi chamada de "Além São Francisco" pela distância que fica da capital da Bahia e pela proximidade com Rio São Francisco. Entre 1964 e 1970, segundo Falcón (2012), a região passou por dificuldades devido à desorganização do sistema fluvial e a desativação do aeroporto na cidade de Barreiras, já que a maioria dos produtos de consumo vinha de fora. O Programa de Desenvolvimento dos Cerrados (PRODECER), em 1985, reintegrou novamente a região, incentivando novos investimentos. A partir dos anos de 1980 houve uma redescoberta do território baiano, tanto pelos próprios baianos, como por imigrantes oriundos de vários estados brasileiros principalmente o sul e sudeste.

A chegada de migrantes e imigrantes preencheram as grandes extensões de mata nativa, com as formas e cores das imensas áreas de terrenos plantados, um extenso mosaico, ao se observar do alto, que surgiu a partir do desmatamento nem sempre consciente. Ao analisar o espaço, que antes era coberto de vegetação, hoje se vislumbra uma paisagem diferente: resultou em quilômetros de lavouras e quase nada de cerrado. As plantações chegam até próximo às rodovias para aproveitar cada pedaço de terra, sem considerar as espécies nativas da flora e da fauna. Não se percebe nenhuma reserva de mata nativa, contribuindo para o desaparecimento da fauna nativa: o cerrado.

A agricultura mecanizada oportunizou o crescimento dos municípios de Luiz Eduardo Magalhães, Barreiras e São Desidério, que se destacam no cenário nacional pelo investimento na produção agrícola. Em contrapartida, em alguns municípios integrantes do Oeste baiano, o desenvolvimento caminha lentamente, sem muitos investimentos do governo, vigorando agricultura de subsistência e predomínio da pecuária. Outro fator é o tipo de terreno nem sempre propenso para a utilização de máquinas.

\section{3. ÁREA DE ESTUDO}

O município de São Desídério foi o local escolhido para a realização da pesquisa, por apresentar inúmeros sítios arqueológicos, contendo inscrições rupestres. O mesmo encontra-se localizado na mesorregião do extremo Oeste Baiano. Possui vasta extensão territorial e condições favoráveis para a agricultura, principalmente o cultivo da soja e do algodão, de acordo com o IBGE(2010), renderam ao município o status de maior produtor nacional de algodão e maior produtor de grãos do Norte / Nordeste.

A pesquisa foi realizada nos sítios arqueológicos, "Morro do Sol" e "Pedras Brilhantes ou Morro dos Tapuias", localizados no município de São Desidério no Estado da Bahia. O sítio Morro do Sol compõe-se de um paredão situado no alto de uma encosta, enquanto que o das Pedras Brilhantes ou Morro dos Tapuias constitui-se de um abrigo principal com teto amplo situado em cima de uma 
pequena serra. A pesquisa se processou com o objetivo de descrever os grafismos rupestres encontrados nos locais. A metodologia utilizada foi à análise descritiva das imagens produzidas no local. A princípio analisaram-se as representações parietais presentes em cada sítio, com ênfase na tipologia, estilos e tradições, considerando as possíveis semelhanças e diferenças encontradas a partir dos aportes teóricos de Ribeiro (2006) ; Oliveira (2006); Prous (2006); Costa (2005) ; Etchevarne (2011); Comerlato (2007), entre outros. Ao final se estabeleceu a comparação croestilística dos grafismos encontrados em cada sítio. A fotografia produzida no local serviu como instrumento para a realização da pesquisa.

\section{RESULTADO DA ANÁLISE PICTOGRÁFICA ENTRE OS SÍTIOS: SEMELHANÇAS E DIFERENÇAS}

Após, análises comparativas entre os sítios pesquisados com outros localizados em algumas áreas brasileiras, a partir dos estudos de Comerlato (2007) chegou-se a algumas conclusões: Os painéis encontrados no Morro do Sol (MS) demonstram melhor estado de visibilidade e conservação. Os grafismos registrados nos dois sítios apresentam semelhanças cronoestilística da Tradição Sanfranciscana, conforme (RIBEIRO, 2006; ETCHEVARNE, 2011), mas, como a pesquisa está apenas no início, ainda faltam dados e maior aprofundamento arqueológico para uma afirmação sobre a possível tradição a que se inserem.

No sítio Pedras Brilhantes (PB), se percebe certa sobreposição. A visualização a olho nu é menor em PB. A distribuição espacial encontrada no sítio PB registra um maior número de grafismo na parte superior, e em sequência horizontal. Em MS o painel com maior concentração de grafismos fica mais próximo do solo, o de menor volume no alto. No PB, identifica-se a cor vermelho vinho não encontrado no outro local. Segundo a classificação de Comerlato (2007) quanto à tipologia, os grupos (A e B) são percebidos em maior número no sítio MS. No decorrer da análise o sítio PB apresentou maior dificuldade de análise devido ao estado de conservação. O sítio MS se encontra geograficamente localizado mais distante da cidade, talvez isso contribua para a melhor conservação encontrada.

\section{CONSIDERAÇÕES FINAIS}

Os grafismos rupestres são representações que descrevem as expressões culturais de períodos distintos. Para compreender o outro e seu modo de vida, o homem sempre buscou explicações em civilizações anteriores, percebendo que as relações de causa e efeito diferem de homens e culturas. As diferenças estilísticas presentes em grafismos de norte a sul do Brasil demonstram que as diferenças culturais são idiossincrásicas. As representações rupestres são compostas por características que variam de acordo com a região onde estão localizadas ou o período de sua elaboração. Em todo território brasileiro é possível encontrar uma infinidade de sítios arqueológicos contendo representações rupestres. Os sítios de 
arte rupestre acompanham a instalação do homem no território brasileiro, se espalham de norte a sul, leste a oeste, ligando-se e adaptando-se as necessidades de sobrevivência.

No município de São Desidério, localizam-se os sítios Morro do Sol e Pedras Brilhantes onde foram analisados três painéis com grafismos rupestres presentes no local. Foi empregado o método descritivo, constatando-se a partir da análise, que apresentam algumas semelhanças com Tradições presentes em outras localidades brasileiras.

Os painéis encontrados no sítio Morro do Sol apresentam menor número de grafismo e maior visibilidade. Os mesmos encontram-se em lugares diferenciados, um mais ao alto, o outro, mais próximo do solo, esse com maior número de registros rupestres. As cores, vermelho e amarelo predominam. O branco foi encontrado em apenas dois grafismos. O preto não aparece.

No sítio das Pedras Brilhantes, os grafismos se apresentam em número acentuado, divididos em pequenos blocos. O conjunto maior se concentra no alto, outro menor abaixo, a uma altura de 2 metros do solo e à sua direita nota-se alguns grafismos soltos. As cores, vermelho e amarelo predominam o branco não aprece. O preto está presente em apenas uma figura. Percebe-se que os grafismos analisados apresentam algumas semelhanças que podem estar relacionadas ao estilo Sanfranciscano.

No decorrer do estudo surgiram dúvidas relacionadas à comparação cronoestilística. A tipologia adotada com base em Comerlato (2007), e os estilos citados por Ribeiro (2006) foram importantes aportes no auxilio das incertezas encontradas durante a realização da análise. Outros problemas encontrados decorreram da falta de aporte teórico na região. No município pesquisado a única biblioteca existente não apresenta nenhuma referência sistematizada aos sítios pesquisados. O que se conseguiu apurar foram apenas relatos desencontrados de pessoas nascidas no município. 


\section{REFERÊNCIAS}

ALMEIDA, Guilherme Albaglide; FARIAS, Luis Henrique. Considerações sobre a Arte Rupestre no Estado da Bahia<http://www.uesb.br/anpuhba>. Acesso em 21 de junho de 2021.

ALVES, Carlos Antonio Belarmino . Evolução da Arqueologia e a falta de Compromisso Governamental. In: OLIVEIRA, Thomas Bruno (org.) . Pré-História II Estudos para a arqueologia da Paraíba. João Pessoa - PB: JRC Gráfica e Editora. 2011.

COSTA, Carlos. Sítios de Representação Rupestre da Bahia (1950-1990):levantamento dos dados primários dos acervos iconográficos das coleções arqueológicas do Museu de Arqueologia e Etnologia da Universidade Federal da Bahia (MAE/UFBA). REVISTA OHUN - Revista eletrônica do Programa de Pós-Graduação em Artes Visuais da Escola de Belas Artes da UFBA Ano 2, nº 2, outubro 2005.

COMERlATO, Fabiana. As Representações Rupestres do Estado de Santa Catarina Brasil . (in). Revista Ohun - Revista Eletrônica do Programa de Pós-Graduação em Artes Visuais da Escola de Belas Artes da UFBA Ano 2, nº 2, outubro 2005.

Estudo Metodológico em Sítios e Gravuras Rupestres em Lajedos, Bahia. In: Congresso da Sociedade de Arqueologia Brasileira, 2007, Florianópolis. Congresso Internacional da SAB. Erechim: Habilis, 2007. P. 1-14.

ETCHEVARNE, Carlos (org.); PMENTEL, Rita.(org.).Patrimônio Arqueológico da Bahia. (Série estudos e pesquisas, 88).1.ed. Salvador: SEI, 2011.132 p.

Ocupação Humana do Nordeste antes da chegada dos Portugueses.

Revista USP, São Paulo, n.44, p. 112-141, dezembro/fevereiro 1999-2000

FAlCóN, Gustavo:(in) Panorama Cultural da Bahia. Panorama Cultural Contemporâneo Regiões Socioculturais: Oeste/ Velho Chico - divisão municipal e principais cidades. Série Estudos e Pesquisas 92. SEP: 2012.Publicações SEI. Salvador 2012. P.311- 322.

GUIDON, N. Pedra Furada: uma revisão. In: Simpósio Internacional O Povoamento das Américas, 2006, São Raimundo Nonato. Artigos e resumos. São Raimundo Nonato: Fundação Museu do Homem Americano, p. 1-8.

ISNARDIS, A. Lapa, Parede, Painel. Distribuição das Unidades Estilísticas dos Grafismos Rupestres do Vale do Rio Peruaçu e suas Relações Diacrônicas (Alto-Médio São Francisco, Minas Gerais). São Paulo: MAE/ USP. Dissertação de Mestrado. 2004.

JORGE, Marcos; PROUS, André: RIBEIRO, Loredana. Brasil Rupestre: Arte pré-histórica brasileira. Curitiba: Zencrane Livros, 2007.

LOURDEAU, Antoine. A Pertinência de uma Abordagem Tecnológica para o Estudo do Povoamento Pré- Histórico do Planalto Central do Brasil. In: Habitus; instituto Goiano da Pré2006. OLIVEIRA ,Lizete Dias de. A Arte Rupestre no Rio Grande do Sul:Semiótica e Estereoscopia. FUMDHAMENTOS VII - 469 disponível em <http://www.fumdham.org.br/> 2006. 
PARELlADA, Claudia Inês. Revista Cientifica/FAP. (in) Arte Rupestre No Paraná. Curitiba, v.4, n.1 p.1-25, jan./jun. 2009.

PESSIS, A. M. Imagens da Pré-história. Parque Nacional da Serra da Capivara. São Paulo: Fumdham- Petrobrás, 2003.

PROUS, A.; SEDA, P. - 1987. Cronologias, Tradições e metodologia na arte Rupestre do Sudeste. Boletim Série Catálogos. Rios de janeiro. Instituto de Arqueologia Brasileira, 177-181.

PROUS, André. Arqueologia Brasileira. Brasília: UNB, 1992.

Recent studies on rock art in Brazil. BAHN, P. G. \& FOSSATI, A. (ed.). Rock Art Studies - News of the World I. Oxbow Monografh, 215- 219.

.Archéologie du Cours Moyen du Rio São Francisco (Vallées dês rios Peruaçu et Cochá). Arquivos do Museu de História Natural. Belo Horizonte: UFMG, v. 17/18, 1996/97.

.Agricultores de Minas Gerais. In: Tenório, M. C. Pré- História da Terra Brasilis. Rio de janeiro: Editora UFRJ. 1999a .

PROUS, A.; RIBEIRO, L. - 2005. A extensão da Tradição Nordeste na América do Sul. XIII Congresso da Sociedade de Arqueologia. Campo Grande.a

RESENDE, Maria Leônia C. de; et al.Mapeamento da Arte Rupestre na Estrada Real. Revista do Arquivo Público Mineiro. MG. Ano 2. 2010, p. 109 a 125.

RIBEIRO, Loredana.Os Significados da Similaridade e do Contraste entre os Estilos Rupestres:um estudo regional das gravuras e pinturas do alto-médio rio são rancisco.Tese Apresentada a Universidade do Estado de São Paulo. 2006. Disponível em: http://www.teses.usp.br

RIBEIRO, L. - 1997. Tradição e ruptura na arte rupestre da Lapa do gigante, Montalvânia?MG. Clio - série Arqueoláogica, 1(12): 177-190.

ROSA. André Luiz. Pré-História em Questão: um breve estudo sobre a arte rupestre em Florianópolis,no Nordeste e na região Amazônica. <http://www.historiaehistoria.com.br>. Acesso em 20 de junho de 2021.

SCHMITZ, P. I.; BARBOSA, A; MIRANDA, A. - 1996. Arqueologia nos Cerrados do Brasil central: sudoeste da Bahia e leste de Goiás - Projeto Serra Geral. Pesquisas, série Antropologia. São Leopoldo, Instituto Anchietano de Pesquisas, n. 52.

SCHMITZ, P. I.; RIBEIRO, M. B.; BARBOSA, M; BARBOSA, A; MIRANDA, A.- 1986. Caiapônia - arqueologia nos cerrados do Brasil central. São Leopoldo, Instituto Anchietano de Pesquisas.

WÜST, I. A Arte Rupestre: seus mitos e seus potenciais interpretativos. In: Ciências Humanas em Revista. Goiânia: UFGO, 2 (1/2), 1991. p.47-74.

Antes: Histórias da Pré- História. Centro Cultural Banco do Brasil. Rio de Janeiro. Brasília. São Paulo, 12 de outubro de 2004 a 09 de janeiro de 2005. 
http://www.cultura.gov.br/.Ministério da Cultura (órgãos e entidades extintas). Acesso em: 22 de junho de 2021.

http://www.censo2010.ibge.gov.br.Acesso em 22 de junho de 2021.

http://www.aiba.org.br/regiao-oeste. Acesso em 07 de janeiro de 2021. 